\title{
Performance of Gel Treatments in Reservoirs with Multiscale Heterogeneity
}

\author{
Ji Ho Lee and Kun Sang Lee \\ Department of Natural Resources and Environmental Engineering, Hanyang University, Seoul 133-791, Republic of Korea \\ Correspondence should be addressed to Kun Sang Lee; kunslee@hanyang.ac.kr
}

Received 5 April 2013; Revised 3 August 2013; Accepted 7 August 2013

Academic Editor: Baojun Bai

Copyright ( $\odot 2013$ J. H. Lee and K. S. Lee. This is an open access article distributed under the Creative Commons Attribution License, which permits unrestricted use, distribution, and reproduction in any medium, provided the original work is properly cited.

\begin{abstract}
Spatially correlated permeability fields are usually generated by single-scale correlation. To overcome the limitations of singlescale permeability fields in describing real situation, permeability fields should be generated by multiscale correlation. Multiscale heterogeneity results in the existence of various permeability magnitudes and spatial distributions of permeability. Gel treatment is applied on the heterogeneous permeability fields realized by multiscale correlation. Performance of gel treatment has been shown to depend on permeability distribution and permeability values, which are determined by correlation length, variance, and number of scales. Generally, spatially-correlated permeability fields generated with longer correlation length, higher variance, and multiscale lead to higher improvement in the performance of gel treatment. In addition, longer application of preflush as waterflooding results in larger reduction of water-oil ratio when the gel treatment is applied to heterogeneous permeability fields after preflush.
\end{abstract}

\section{Introduction}

Most of reservoirs are geologically complex and show the heterogeneity because of various distributions of porosity and permeability, deposition, and natural fractures. Among many heterogeneous petrophysical properties, permeability is the most important factor for reservoir engineering calculations. Heterogeneous permeability system leads to different flow movements in reservoir compared with the equivalent homogeneous system. Van Poolen [1] indicated that variations in permeability distribution caused a significant impact on the oil recovery and water production during enhanced oil recovery, which means that oil recovery by the injection of materials does normally not exist in the reservoir [2]. As long as heterogeneity of permeability distribution is increased, flow mechanism becomes more complex. Even though the average permeability of reservoir is the same, the distribution of permeability leads the performance of enhanced oil recovery makes totally different.

As the reservoirs have more severe heterogeneity, there is more severe permeability contrast. If waterflooding is applied on such highly heterogeneous fields, injected water flows mainly through high-permeability zones. This flow pattern makes the injected water unable to sweep substantial oil located in low-permeability zones, but it is produced directly at producer, the so-called conformance problem. According to Portwood et al. [3], parts of the Healdton Field in Carter County, Ok, USA, showed high watercut because of complex permeability distributions. Excessive water production could make the life of the well short because of high water disposal cost. For this reason, controlling of water production is of significant importance. To overcome excessive water production by improving volumetric sweep efficiency, especially vertical sweep efficiency, cross-linked polymer gel is widely used. Gel treatment uses polymer and cross-linker. Cross-linker makes polymer form networks, so that it has high capability to plug pore. Due to its promising permeability reduction capability, gel treatment is evidently of great conformance control $[4,5]$.

There are several types of gel treatment, such as the in situ bulk gel and microgel. In situ bulk gel is formed with high concentration of polymer and cross-linker representing substantial polymer network. Because of strong gel due to great amount of polymer network, it hardly flows well through small pores in matrix. Owing to relatively slow flow capacity, bulk gel is appropriate to treat high-permeability zones near well bores or reservoirs containing fractures. By contrast, in 
situ microgel is formed with relatively low concentration of polymer and cross-linker. The microgel is able to penetrate deeper into a formation until its gelation mechanism is triggered. Therefore, it is appropriate for reservoirs that have indepth high-permeability zones or that do not have fractures. Randomly heterogeneous reservoirs considered in this study have various locations of high-permeability zones without fractures; thus in situ microgel is selected.

In the recent years, preformed particle gels (PPGs) have been proposed and developed by Coste et al. and Bai et al. $[6,7]$. They are oriented to overcome some distinct drawbacks inherent in the in situ gelation systems such as lack of gelation time, uncertainness of gelling due to shear, degradation, chromatographic fractionation, or change of gelant composition, and dilution by formation water [7]. They are categorized as preformed gels for conformance control, which is of great interest to several researchers [6-12]. There are also pH-triggered microgels and temperature-triggered microgels, called the Bright Water for application to specific reservoir conditions. However, this study utilizes in situ microgel to assess the performance of gel treatment with respect to not only water production but also gelation under general conditions.

According to the studies on the performance of gel treatment, heterogeneity of reservoir permeability has been revealed to be the most important factor among influential factors like other EOR methods. Also, previous investigations had been focused on layered permeability system in vertical direction [13-15]. It was revealed that high-permeability contrast of layered system significantly improves the performance of gel treatment $[13,14]$. However, these layered reservoir systems are hard to be assumed as realistic reservoirs. In advance of researches for layered heterogeneous system, several researches for spatially correlated heterogeneous fields have been conducted in terms of enhanced oil recovery [16, 17]. However, these researches also assumed that heterogeneous permeability fields have single-scale correlation, so they still have limitation to generate various and proper realistic permeability fields.

In the field of groundwater flow, aquifer heterogeneity is important as much as reservoir heterogeneity in petroleum engineering. Groundwater and solute transport processes in the aquifer are considerably affected by the heterogeneity of the formation properties [18]. Many researchers developed theories based on the assumption that the spatial distributions of the medium properties can be characterized by one single-scale correlation [19]. However, when heterogeneity at any scale cannot be averaged out, nor can be treated as a deterministic trend, single-scale correlation approach is invalid [19]. In addition, as many subrandom fields compose of parent random field, that is, each layer, which has various geological conditions, gathers and consists of aquifer, single-scale correlation method lacks the ability to produce this model [19]. A number of reasons including deformation and solution could alter the characteristics of reservoir depending on scale. Therefore, generation of more proper fields should include both local and regional correlations, that is, multiscale correlation, so a few researchers investigated nonstationary multiscale correlation [19]. However, researches considering multiscale heterogeneity of permeability have not been conducted substantially, especially for EOR. This study accesses the performance of gel treatment applied on spatially correlated heterogeneous fields considering multiscale spatial correlation.

We neglect time-dependent term and suppose that stationary multiscale focuses on how the multiscale, combination of local scale and regional scale, affects heterogeneity and performance of gel treatment by comparing with single scale. In addition to multiscale effect, effect of spatial correlation, which is represented with correlation length and variance, on heterogeneity and performance of gel treatment is evaluated. The Dykstra-Parsons coefficient is used to quantify the level of heterogeneity of all permeability fields used in the simulations. Distribution of permeability and permeability reduction factor of gel placement are shown with figures, which could not been clarified through the Dykstra-Parsons coefficient. It is also investigated how preflush as waterflooding influences the performance of gel treatment applied on heterogeneous permeability field. Because preflush before gel treatment could control location of gelation, investigation of preflush is of importance.

\section{Basic Theories}

2.1. Gel Treatment. Due to pore-blocking mechanism, gel treatment improves sweep efficiency and is known as an effective conformance control. However, the exact mechanism is still uncertain. The uncertainty arises from whether gel mainly penetrates high-permeability zones as intended. Cozic et al. and Seright et al. suggested steric effect, which assumes that microgel solution acts as water flows during injection $[20,21]$. Zaitoun et al. insisted that relatively large microgel size results in low amount of microgel penetration of low-permeability zones [22]. Several authors suggested and explained the disproportionate permeability reduction (DPR) effects or sometimes called relative permeability modification (RPM) effects [11, 23-26]. According to DPR, it reduces relative water permeability dominantly rather than relative oil permeability, even if gel solution penetrates both low- and highpermeability zones. However, major mechanisms of gel treatment are related to permeability reduction by pore plugging and DPR, which are considered as main mechanisms in this study.

This study models polymer/chromium chloride gel. In the process of polymer/chromium chloride gel, two reactions and kinetics, that is, redox and gelation reactions, occurred. Substantive gelation process is the reaction between trivalent chromium $\left(\mathrm{Cr}^{3+}\right)$ and polymer to form gel. Because this reaction process is so fast, an additional reaction, that is, redox reaction, is implemented to delay this fast reaction. Fast gelation misleads to placing the gel intensively near the well bore, not in high-permeability zones, and it could decrease injectivity and productivity. To control gelation time, two reactions usually participate to gelation. The first reaction of in situ gelation is redox reaction of sodium dichromate with reducing agent, that is, thiourea $\left(\mathrm{CS}\left(\mathrm{NH}_{2}\right)_{2}\right)$ generating trivalent 
chromium. For the second reaction, the generated trivalent chromium forms gel with polymer as follows:

$$
\begin{gathered}
\mathrm{Cr}_{2} \mathrm{O}_{7}^{2-}+6 \mathrm{CS}\left(\mathrm{NH}_{2}\right)_{2}+8 \mathrm{H}^{+} \\
\stackrel{k}{\longrightarrow} 2 \mathrm{Cr}^{3+}+3\left[\mathrm{CS}\left(\mathrm{NH}_{2}\right)_{2}\right]_{2}+7 \mathrm{H}_{2} \mathrm{O} \\
\mathrm{Cr}^{3+}+\text { POLYMER } \longrightarrow \text { Gel. }
\end{gathered}
$$

The kinetics for the reaction of polymer and trivalent chromium are implemented with the following expression of exponents:

$$
\begin{gathered}
\frac{d\left[\mathrm{Cr}^{3+}\right]}{d t}=-k \frac{\left[\mathrm{Cr}^{3+}\right]^{\mathrm{X} 14}[\text { polymer }]^{X 4}}{\left[\mathrm{H}^{+}\right]^{X 16}}, \\
\frac{d[\text { gel }]}{d t}=-\frac{1}{n} \frac{d\left[\mathrm{Cr}^{3+}\right]}{d t},
\end{gathered}
$$

where $X 4, X 14$, and $X 16$ are exponents to be used for each component in gelation reaction and $k$ is kinetic rate coefficient for gel.

Because gel reaction is extremely sensitive to temperature as other chemical reactions, temperature effect is very critical to decide whether gel treatment is applicable or not. The effect is reflected in kinetic rate coefficient shown in (3). Temperature dependence of kinetic rate coefficient is represented with the Arrhenius equation as follows:

$$
k=k_{\text {ref }} \exp \left\{k_{T}\left(\frac{1}{T}-\frac{1}{T_{\text {ref }}}\right)\right\}
$$

where $k_{\text {ref }}$ is kinetic reaction coefficient at reference temperature, $k_{T}$ is parameter for calculating kinetic rate coefficient for gel as a function of reservoir temperature, $T$ is the reservoir, temperature calculated from solving energy balance equation and $T_{\text {ref }}$ is reference temperature assumed to be equal to reservoir temperature.

DPR, resulting by adsorption of gel onto surface of pore, is utilized due to its ability to compress/collapse/dehydrate in presence of water-oil capillary pressure. The adsorption is calculated by the Langmuir-type isotherm equation with gel concentration in the aqueous phase as follows:

$$
\overline{C_{15}}=\frac{a_{15} C_{15,1}}{1+b_{15} C_{15,1}},
$$

where $\overline{C_{15}}$ is the concentration of adsorbed gel and $a_{15}$ and $b_{15}$ are gel adsorption parameters.

The effect of gel on aqueous-phase permeability reduction reflecting pore plugging mechanism and DPR is represented with permeability reduction factor, which is an index of capacity to modify the flow in reservoirs. Permeability reduction factor, $R_{\mathrm{RF}}$, is defined as effective aqueous-phase permeability ratio of the before-to-after gel treatment as follows;

$$
\begin{gathered}
R_{\mathrm{RF}}=1+\frac{\left(R_{\mathrm{RF} \max }-1\right) A_{g k} C_{15,1}}{1+B_{g k} C_{15,1}}, \\
R_{\mathrm{RF} \text { max }}=\left[1-\frac{c_{r g}\left(A_{p 1} C_{\mathrm{SEP}}^{S_{p}}\right)^{1 / 3}}{\left(\sqrt{\left(k_{x} k_{y}\right)} / \phi\right)^{1 / 2}}\right]^{-4}, \\
C_{\mathrm{SEP}}=\frac{C_{5,1}+\left(\beta_{p}-1\right) C_{6,1}}{C_{1,1}},
\end{gathered}
$$

where $R_{\mathrm{RF} \text { max }}$ is the maximum residual resistance factor, $A_{g k}$ and $B_{g k}$ are the permeability reduction parameters for the Langmuir correlation with gel concentration, $C_{15,1}$ is the concentration of gel in aqueous phase, $c_{r g}$ is the constant depending on gel type, $A_{p 1}$ is the parameter to calculate polymer viscosity at zero shear rate, $C_{\mathrm{SEP}}$ is the effective salinity, $S_{p}$ is the slope of viscosity versus effective salinity on a log-log plot, $k_{x}$ and $k_{y}$ are the permeabilities of $x$ and $y$ directions, $\phi$ is the porosity, $C_{5,1}, C_{6,1}$, and $C_{1,1}$ are the anion, divalent cation and water component concentrations in aqueous phase, and $\beta_{p}$ is the parameter to combine divalent cation, salinity with anion salinity.

Increased viscosity of injection fluid by injected polymer or formed gel reduces conformance problem. The viscosity of aqueous phase containing gel and polymer is modeled with the Flory-Huggins equation as follows:

$$
\begin{aligned}
\mu_{1}=\mu_{w}[1 & +\left(A_{p 1} C_{4,1}+A_{p 2} C_{4,1}^{2}+A_{p 3} C_{4,1}^{3}\right) C_{\mathrm{SEP}}^{S_{p}} \\
& \left.+A_{g 1} C_{15,1}+A_{g 2} C_{15,1}^{2}\right]
\end{aligned}
$$

where $C_{4,1}$ is the concentration of polymer, $A_{p 1}, A_{p 2}$, and $A_{p 3}$ are parameters to calculate polymer viscosity at zero shear rate, and $A_{g 1}$ and $A_{g 2}$ are the Flory-Huggins parameters for gel viscosity.

2.2. Random Field Generation. Recognition of permeability is critical to predict oil recovery process by numerical reservoir simulation. Permeability shows not perfectly random distribution but some correlation structures. Therefore, synthetic permeability fields could be realized in a stochastic method to simulate natural variety $[27,28]$. Permeability is considered as a random variable and is assumed to have its own density function as log-normal distribution. To generate permeability random fields, second-order stationarity is assumed. Based on second-order stationarity, covariance function, correlation length, and variance are given. Correlation length is the lag distance at which the values at two locations are marginally dependent on each other [29].

Generation of heterogeneous permeability field is performed with the IGW software, which is developed for unified deterministic and stochastic groundwater modeling [30]. Based on efficient computational algorithms, IGW simulates complex flow and geological heterogeneity. Heterogeneous 




(a) Homogeneous permeability field

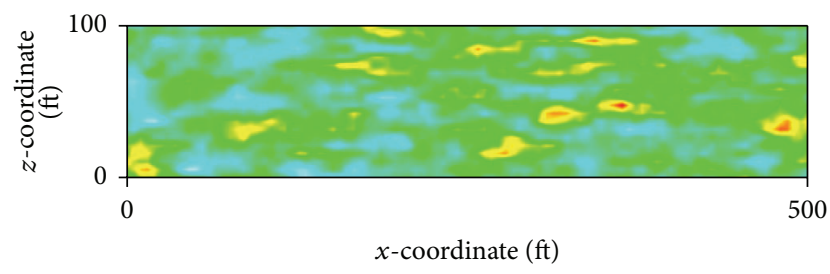

(c) (1) $\lambda_{x}=20, \lambda_{z}=5, \sigma=3$



(e) (1) $\lambda_{x}=20, \lambda_{z}=5, \sigma=1$ and (2) $\lambda_{x}=40, \lambda_{z}=10, \sigma=1$



(b) (1) $\lambda_{x}=20, \lambda_{z}=5, \sigma=1$

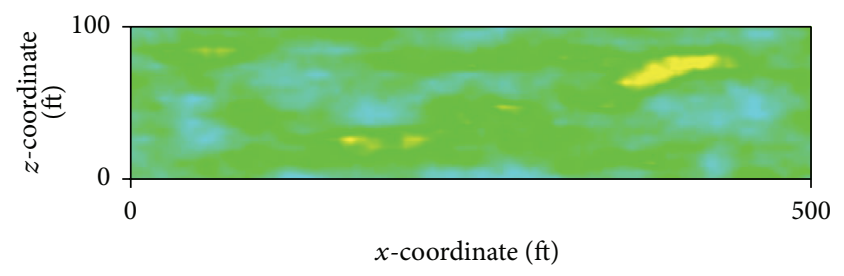

(d) (1) $\lambda_{x}=40, \lambda_{z}=10, \sigma=1$

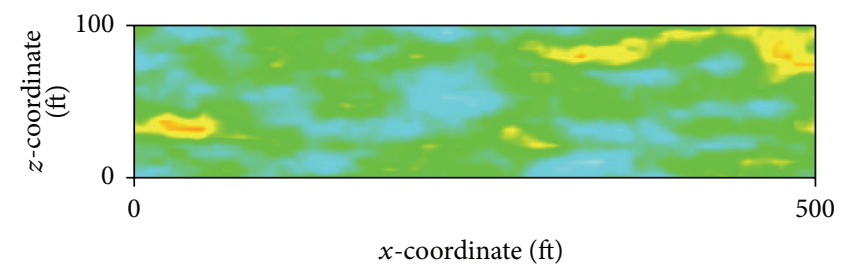

(f) (1) $\lambda_{x}=20, \lambda_{z}=5, \sigma=1$ and (2) $\lambda_{x}=40, \lambda_{z}=10, \sigma=2$

Figure 1: Homogeneous permeability field (a) and heterogeneous permeability fields depending on single-scale correlation ((b), (c), and (d)) and multiscale correlation ((e) and (f)) expressed with $\ln k$.

permeability fields are generated by unconditional random process, given with correlation lengths for $x$ and $z$ directions $\left(\lambda_{x}, \lambda_{z}\right)$, variances $(\sigma)$, and several covariance functions.

This study aims to investigate multiscale correlation, correlation length, and variance, as shown in Figure 1. Permeability varies significantly in space, so the distribution is presented by natural logarithm of permeability $(\ln k)$.

\section{Numerical Modeling}

Modeling gel treatment on a spatially correlated heterogeneous permeability field is conducted with UTCHEM. UTCHEM performs a 3D, multicomponent, and multiphase compositional model of chemical flooding process considering complex phase behavior, chemical and physical transformation, and heterogeneous porous media properties [31]. It is known as one of the advanced simulators for chemical flooding process.

This study analyzes the heterogeneity and performance of gel treatment in multiscale heterogeneous permeability fields compared with those of single-scale heterogeneous fields. 2D cross-sectional model of reservoir is considered for the analysis. The hypothetical reservoir locates at $1,300 \mathrm{ft}$ depth and has initial pressure and temperature as $200 \mathrm{psi}$ and $103^{\circ} \mathrm{F}$, respectively. The cross-sectional area is $500 \times 100 \mathrm{ft}^{2}$. There is a two-phase flow in the reservoir, so initial saturations of water and oil are assumed to be 0.3 and 0.7 , respectively. Porosity has uniform value of 0.2 over the whole reservoir because the variation of porosity is not severe as much as that of the permeability. When vertical communication of fluid is high in the reservoirs, the efficiency of gel treatment decreases. In addition, geological processes make the vertical permeability much lower than horizontal permeability. Reflecting these observations, the ratio of vertical-to-horizontal permeability is set to be 0.01 .

Effects of gel treatment are determined for the typical design of injection process. Injection of fluids and production are continued for 1,000 days. When enhanced oil recovery method is applied, preflush as waterflooding is usually recommended to get higher productivity, so preflush is applied before gel treatment. Rate of injection fluid is maintaind as $2,000 \mathrm{ft}^{3} /$ day. After preflush is finished, injection of polymer and $\mathrm{Cr}^{3+}$ starts at in 510 days and continues until 525 days, as shown Figure 2. After that, postflush as also waterflooding is resumed. Concentrations of polymer and $\mathrm{Cr}^{3+}$ are shown in Figure 2. All detailed input data for petrophysical properties of the reservoir, kinetics of gelation, temperature effect on the reaction, permeability reduction factor, viscosity, and adsorption are summarized in Table 1.

Covariance function is required to realize spatially correlated heterogeneous permeability field. Single-scale correlation method needs just one covariance function, while 
TABLE 1: Input data of reservoir property and gel reaction.

\begin{tabular}{|c|c|}
\hline Parameters & \\
\hline \multicolumn{2}{|l|}{ Reservoir } \\
\hline Porosity, $\phi$ & 0.2 \\
\hline Ratio of vertical-to-horizontal permeability, $k_{v} / k_{h}$ & 0.01 \\
\hline Depth (ft) & 1,300 \\
\hline Temperature $\left({ }^{\circ} \mathrm{F}\right)$ & 103 \\
\hline Pressure (psi) & 200 \\
\hline Compressibility, $c_{f}\left(\mathrm{psi}^{-1}\right)$ & 0 \\
\hline \multicolumn{2}{|l|}{ Initial saturation } \\
\hline Water, $S_{\mathrm{wi}}$ & 0.3 \\
\hline Oil, $S_{\mathrm{oi}}$ & 0.7 \\
\hline Initial hydrogen ion concentration (meq/mL) & 160 \\
\hline \multicolumn{2}{|l|}{ Kinetics of gelation } \\
\hline$X 4$ & 0.8 \\
\hline$X 14$ & 1.32 \\
\hline$X 16$ & 1 \\
\hline$k_{\text {ref }}\left(\left(\text { mole } / m^{3}\right)^{1-X 14-X 4+X 16}\right.$ days $\left.^{-1}\right)$ & 15 \\
\hline$k_{T}\left({ }^{\circ} \mathrm{K}^{-1}\right)$ & $-22,344$ \\
\hline SCR & 0.25 \\
\hline \multicolumn{2}{|l|}{ Permeability reduction factor } \\
\hline$A_{\mathrm{gk}}$ & 0.06 \\
\hline$B_{\mathrm{gk}}$ & 0.099 \\
\hline$c_{\mathrm{rg}}\left(\mathrm{m} \cdot \mathrm{wt} . \%^{1 / 3}\right)$ & $4.9674 \times 10^{-7}$ \\
\hline$A_{\mathrm{pl}}\left(\mathrm{wt} . \%^{-1}\right)$ & 80 \\
\hline \multicolumn{2}{|l|}{$C_{\mathrm{SEP}}$} \\
\hline$\beta_{p}$ & 10 \\
\hline$C_{\mathrm{SEPmin}}\left(\mathrm{meq} / \mathrm{m}^{3}\right)$ & 10,000 \\
\hline$S_{p}$ & 0.169 \\
\hline \multicolumn{2}{|l|}{ Viscosity } \\
\hline$A_{\mathrm{g} 1}\left(\mathrm{cp} \mathrm{ppm} \mathrm{pm}^{-1}\right)$ & 0.008 \\
\hline$A_{\mathrm{g} 2}\left(\mathrm{cp} \mathrm{ppm}{ }^{-2}\right)$ & $2.7 \times 10^{-5}$ \\
\hline \multicolumn{2}{|l|}{ Adsorption } \\
\hline$a_{15}($ vol. of water/ppm of chromium $)$ & 1,157 \\
\hline$b_{15}$ (vol. of water/ppm of chromium) & 100 \\
\hline
\end{tabular}

multiscale correlation method requires two covariance functions. Similarly, one correlation length for each direction and one theoretical variance are needed to generate realization of single scale correlated random field. Multiscale-correlated random fields need two correlation lengths for each direction and two variances. Tables 2 and 3 summarize the variables used to generate permeability fields for Cases 1 to 5 in this study. With these variables, 50 equivalent realizations have been generated for each case, and heterogeneity has been investigated by means of heterogeneity index and visualized image. In addition, gel treatment is applied to heterogeneous permeability fields to investigate the effects of heterogeneity on the performance of gel treatment. Representative realized fields among a number of fields for each case are visualized in Figure 1 including homogeneous permeability field having equivalent permeability as $200 \mathrm{md}$. These representative example heterogeneous permeability fields for each case will be named as Ex 1 to 5 to differentiate Cases 1 to 5 .

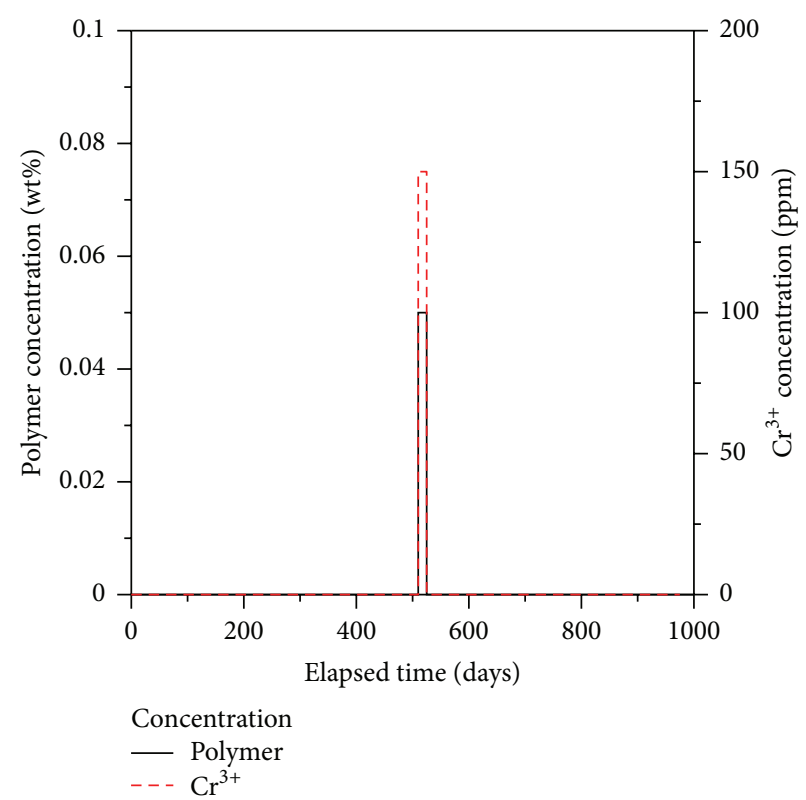

FIGURE 2: Injection history of concentrations for polymer and $\mathrm{Cr}^{3+}$.

TABLE 2: Variables for single-scale correlation.

\begin{tabular}{lccc}
\hline & Case 1 & Case 2 & Case 3 \\
\hline Covariance function & Bell & Bell & Bell \\
$\gamma_{x}$ & 20 & 20 & 40 \\
$\gamma_{z}$ & 5 & 5 & 10 \\
$\sigma$ & 1 & 3 & 1 \\
Horizontal permeability (md) & 200 & 200 & 200 \\
\hline
\end{tabular}

TABLE 3: Variables for multiscale correlation.

\begin{tabular}{ccc}
\hline & Case 4 & Case 5 \\
\hline Covariance function & Bell & Bell \\
$\gamma_{x}$ & 20 & 20 \\
$\gamma_{z}$ & 5 & 5 \\
$\sigma$ & 1 & 1 \\
Covariance function & Exponential & Exponential \\
$\gamma_{x}$ & 40 & 40 \\
$\gamma_{z}$ & 10 & 10 \\
$\sigma$ & 1 & 2 \\
Horizontal permeability $(\mathrm{md})$ & 200 & 200 \\
\hline
\end{tabular}

\section{Results}

4.1. Heterogeneity. Based on the preliminary simulation results, heterogeneities of five cases are investigated. As permeability is characterized as log-normal distribution, the Dykstra-Parsons coefficient is used to define permeability variation as follows:

$$
V_{k}=\frac{k_{50}-k_{84.1}}{k_{50}},
$$

where $k_{50}$ is the permeability value with $50 \%$ probability and $k_{84.1}$ is the permeability value with $84.1 \%$ probability. 
TABle 4: The Dykstra-Parsons coefficients of 50 fields for each case.

\begin{tabular}{lccccc}
\hline & Case 1 & Case 2 & Case 3 & Case 4 & 0.764 \\
\hline$\# 1$ & 0.636 & 0.785 & 0.632 & 0.748 \\
$\# 2$ & 0.595 & 0.789 & 0.600 & 0.764 & 0.780 \\
$\# 3$ & 0.753 & 0.831 & 0.623 & 0.705 & 0.822 \\
$\# 4$ & 0.771 & 0.593 & 0.740 & 0.804 \\
$\# 5$ & 0.776 & 0.792 & 0.513 & 0.700 & $\vdots$ \\
$\# 6$ & 0.818 & 0.764 & 0.591 & 0.847 \\
$\vdots$ & 0.693 & $\vdots$ & $\vdots$ & 0.729 & $\vdots$ \\
$\# 49$ & $\vdots$ & 0.803 & 0.619 & 0.771 \\
\hline 50 & 0.814 & 0.766 & 0.537 & 0.769 \\
\hline
\end{tabular}

Although this is a useful tool for characterizing the degree of reservoir heterogeneity, it does not have information on the spatial distribution of fields. To analyze the reservoir heterogeneity quantitatively and to get information of distribution, not only the Dykstra-Parsons coefficient but also the images of permeability are utilized, as shown in Figure 1. Table 4 briefly shows the Dykstra-Parsons coefficients for each realized field for each case. Arithmetic mean of generated 50 geometric permeability means for each case and arithmetic mean of the realized Dykstra-Parsons coefficients for each case are introduced to analyze degrees of heterogeneity statistically and are represented in Table 5.

With respect to Dykstra-Parsons coefficient, generated heterogeneous permeability fields have various heterogeneities depending on the correlation length, the variance, and the number of scales. It is easily identified that higher variance and multiscale result in higher heterogeneity in a range of 0.6 to 0.85 from Table 4 . Table 5 summarizes the simulation results of heterogeneous fields. Based on the heterogeneity index, $V_{k}$ values of Cases 1 and 3 are over 0.5 , so the two cases are moderately heterogeneous. Cases 2, 4, and 5, where $V_{k}$ values are over 0.7 , are extremely heterogeneous. From the results, it is concluded that impacts of variables, that is, correlation length, variance, and number of scales, are definitely different. Variance influences heterogeneity index more significantly than correlation length. In multiscalecorrelated heterogeneous fields, heterogeneity index is higher than single-scale-correlated heterogeneous fields because of inclusion of locally correlated relation within regionally correlated relation as shown in comparison between Cases 3 and 4 or between Cases 1 and 4 . In the comparison between Cases 2 and 4, single-scale cases show higher heterogeneity index than multiscale cases. This inconsistency resulted due to higher variance in single-scale cases. To evaluate the multiscale effect only, either of local scale or regional scale of multiscale should have the same spatial correlation with single scale. For this reason, comparison between Cases 3 and 4 or between Cases 1 and 4, not between Cases 2 and 4, is appropriate to assess multiscale effect.

Heterogeneity should be investigated with not only heterogeneity index but also visualized permeability image. Because the Dykstra-Parsons coefficient just arranges all permeabilities in order of magnitude to calculate heterogeneity quantitatively, it lacks spatial distribution information of
TABLE 5: Arithmetic means of geometric permeability means and the Dykstra-Parsons coefficients for each case.

\begin{tabular}{lcc}
\hline & $\begin{array}{c}\text { Geometric mean of } \\
\text { permeability }\end{array}$ & $\begin{array}{c}\text { The } \\
\text { Dykstra-Parsons } \\
\text { coefficient }\end{array}$ \\
\hline Case 1 & 197 & 0.587 \\
Case 2 & 197 & 0.788 \\
Case 3 & 207 & 0.597 \\
Case 4 & 202 & 0.733 \\
Case 5 & 200 & 0.814 \\
\hline
\end{tabular}

permeability, as shown in Figure 1. For example, even though correlation lengths are different between Cases 1 and 3, the Dykstra-Parsons coefficients are similar. Accordingly, investigation of spatial permeability distribution on fields is conducted with permeability field images. From the Figures 1(b) and $1(\mathrm{~d})$, longer correlation length produces spatial distribution to be more layered system in spite of the similar DykstraParsons coefficients. It is due to longer $x$-direction correlation length for Case 3 than Case 1. From the comparison of permeability fields between Figures 1(b) and 1(c), it is clearly seen that extremely large values of permeability are shown easily in the higher variance case. However, both cases have the same correlation length, so the spatial distribution of both cases seems to be similar. Case 4 has two scales: the first one shows local correlation, and the second one shows regional correlation. Local correlation is the same with Case 1, and regional correlation is the same with Case 3. Because correlation length defines the spatial distribution of permeability, Case 4 follows similar spatial distribution of both Cases 1 and 3. It has more layered system than Case 1, but a less layered one than Case 3. Multiscale correlation shows local and regional relationship simultaneously. In addition, multiscale correlation has higher heterogeneity than both Cases 1 and 3. To make sure that higher variance could represent higher heterogeneity in multiscale correlation, the second scale of Case 5 is set to have higher variance than that of Case 4. As expected, higher variance leads to higher heterogeneity in multiscale correlation. From these results, multiscale correlation could broaden generation of synthetic heterogeneous fields variously. 




(a) Nontreated waterflooding

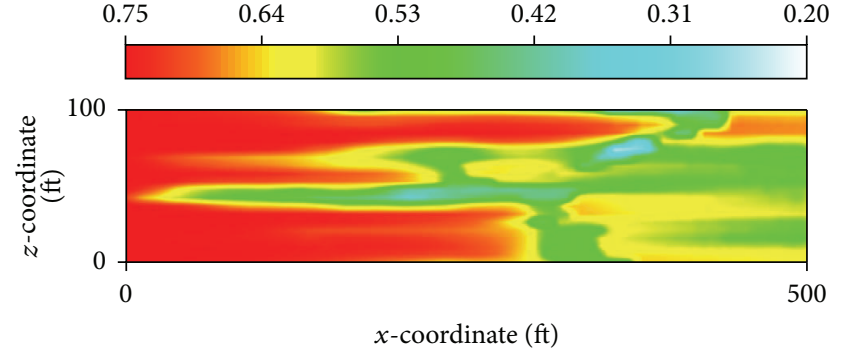

(b) Gel-treated waterflooding

FIGURE 3: Comparison of water saturations between nontreated waterflooding and gel-treated waterflooding at 640 days.

TABLE 6: Produced water-oil ratio after gel treatment at 1,000 days.

\begin{tabular}{|c|c|c|c|c|c|c|}
\hline & Case 1 & Case 2 & Case 3 & Case 4 & Case 5 & Homogeneous \\
\hline$\# 1$ & 20 & 21 & 28 & 27 & 21 & \multirow{9}{*}{45} \\
\hline$\# 2$ & 29 & 32 & 45 & 27 & 10 & \\
\hline$\# 3$ & 52 & 11 & 27 & 12 & 32 & \\
\hline$\# 4$ & 31 & 24 & 21 & 24 & 22 & \\
\hline \#5 & 57 & 11 & 34 & 17 & 6 & \\
\hline \#6 & 33 & 17 & 19 & 28 & 30 & \\
\hline$\vdots$ & $\vdots$ & $\vdots$ & $\vdots$ & $\vdots$ & $\vdots$ & \\
\hline \#49 & 30 & 9 & 18 & 36 & 16 & \\
\hline \#50 & 35 & 25 & 24 & 17 & 17 & \\
\hline
\end{tabular}

4.2. Gel Treatment. Results from the previous study indicate that multiscale correlation usually generates more heterogeneous field than single-scale correlation. With these generated heterogeneous fields, analysis of gel treatment performance is conducted; that is, how much gel treatment improves productivity, reduction of water production, and when gel treatment is applied on single-scale- or multiscalecorrelated heterogeneous permeability fields.

Because main purpose of gel treatment is to reduce excessive water production, gel treatment performance is mainly analyzed with water-oil ratio (WOR). Figure 3 presents comparison of water saturation between gel-treated and nontreated waterflooding at 640 days. The corresponding permeability field is an Ex 5, as shown in Figure 1(f). Figure 3 confirms that gel treatment is effective not only to delay the outbreak of water breakthrough at producer but also to improve vertical sweep efficiency.

Table 6 lists the results of water-oil ratio at the end of production. All realized heterogeneous fields have similar geometric mean of permeability of $200 \mathrm{md}$. To investigate all results statistically, arithmetic means of WOR and cumulative oil recovery for gel treatment on 50 generated permeability fields for all cases are analyzed and summarized in Table 7. To investigate the influence of heterogeneity on gel treatment performance, results from homogeneous permeability field are considered as a base. From the homogeneous field case, it is certain that gel treatment reduces water-oil ratio as much as $78 \%$. In comparison with homogeneous field, all gel treatments on Cases 1 to 5 reduce water-oil ratio more than $17 \%$, as illustrated in Tables 6 and 7. The best improvement of wateroil ratio is observed in Case 5 at the end of production, which
TABLE 7: Arithmetic means of water-oil ratio and cumulative oil recovery after gel treatment at the 1,000 days.

\begin{tabular}{lcc}
\hline & Water-oil ratio & $\begin{array}{c}\text { Cumulative oil } \\
\text { recovery }\end{array}$ \\
\hline $\begin{array}{l}\text { Nontreated } \\
\text { homogeneous field }\end{array}$ & 206 & 0.62 \\
$\begin{array}{l}\text { Gel-treated } \\
\text { homogeneous field }\end{array}$ & 45 & 0.62 \\
Case 1 & 31 & 0.59 \\
Case 2 & 18 & 0.52 \\
Case 3 & 37 & 0.59 \\
Case 4 & 23 & 0.55 \\
Case 5 & 17 & 0.51 \\
\hline
\end{tabular}

is about $63 \%$ reduction of that for gel-treated homogeneous field case. Even though heterogeneous field has equivalent geometric mean of permeability to homogeneous field, application of gel treatment on heterogeneous field results in less water-oil ratio than on homogeneous field because of heterogeneity. Tables 6 and 7 also prove that gel treatment on heterogeneous field having higher heterogeneity index leads to lower water-oil ratio than on heterogeneous field having lower heterogeneity index. With respect to cumulative oil recovery, gel treatment does not have effectiveness due to DPR mechanism.

Figures 4(b) to 4(f) present permeability reduction factor calculated from simulations by applying gel treatment to Ex 1 to 5 fields which are representative heterogeneous permeability fields shown in Figures 1(b) to 1(f). Figure 4(a) just 


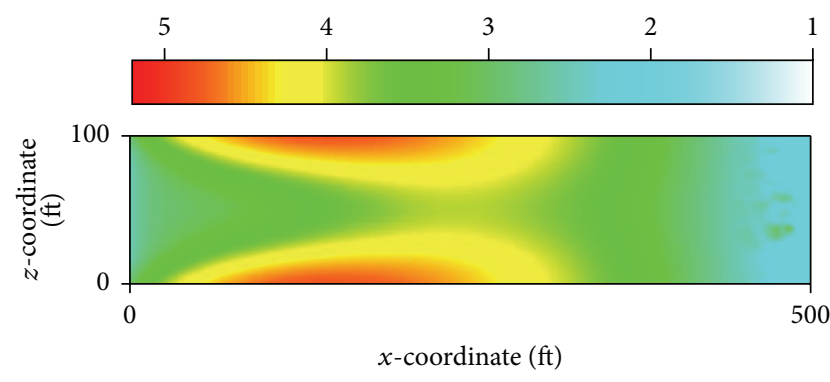

(a) Homogeneous field

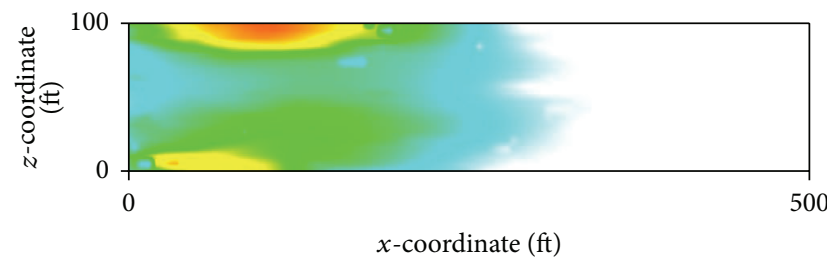

(c) Case 2

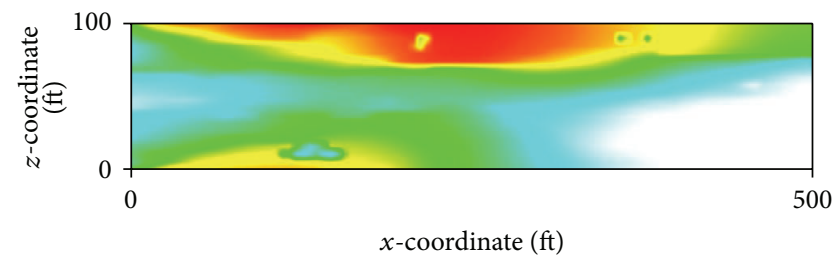

(e) Case 4

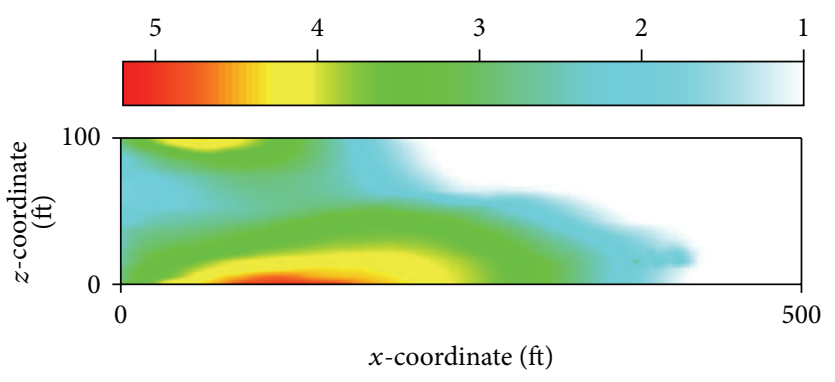

(b) Case 1



(d) Case 3

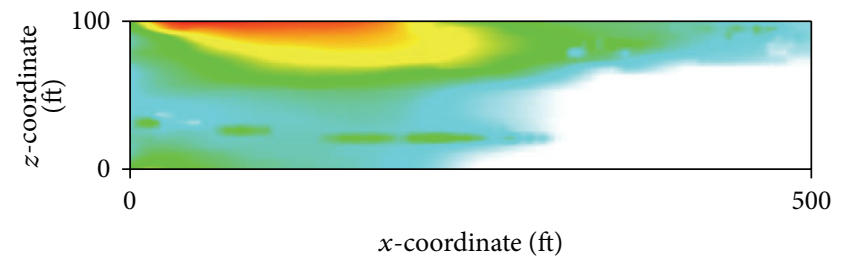

(f) Case 5

FIgURE 4: Permeability reduction factors depending on heterogeneity at 1,000 days.

shows the permeability reduction factor when gel treatment is applied on equivalent homogeneous permeability field. Successful gel treatment means placing gel in a proper location, that is, high-permeability zone. For the homogeneous field, nonperturbation of permeability sustains the front of gel solution to advance steady. Regarding heterogeneous fields, as shown in Figures 4(b) to 4(f), gel is placed in mainly highpermeability zone. Among heterogeneous fields, gel treats almost whole domain in multiscale correlation (Figures 4(e) and $4(\mathrm{f})$ ) and single scale correlation field having longer correlation length (Figure 4(d)). The results are consistent with previous results in that correlation length controls spatial distribution of permeability, that is, degree of layered permeability system. For Case 3, gel could spread on whole domain in spite of single-scale correlation because of longer correlation length. In a multiscale correlation field, regional scale having longer correlation length induces more layered permeability field, so gel spreads on whole area of reservoir. By comparing Cases 3 and 4, adding local scale to regional scale makes heterogeneity more severe, so this makes gel present in high-permeability zones intensively.

Figure 5 shows improvements of water-oil ratio in geltreated waterflooding compared with nontreated waterflooding as a function of time for Ex 1 to 5. It is hard to be certain that comparison among Ex 1 to 5 represents all information of every gel treatment on realized permeability field. However,

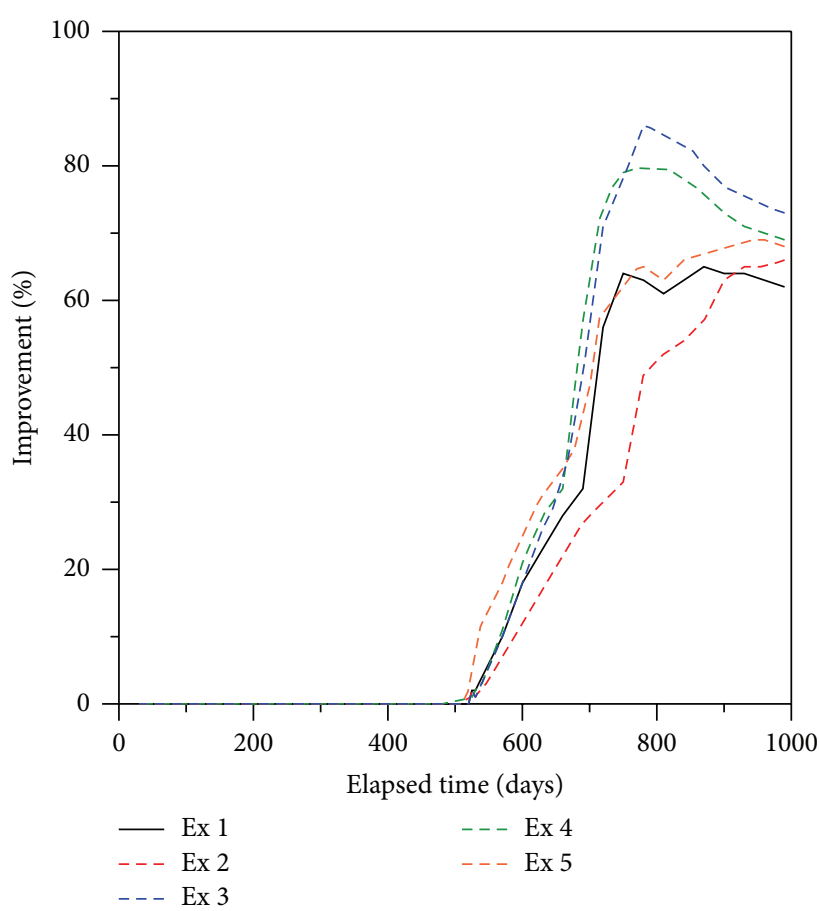

FIGURE 5: Improvements of water-oil ratio between nontreated waterflooding and gel-treated waterflooding according to elapsed time. 


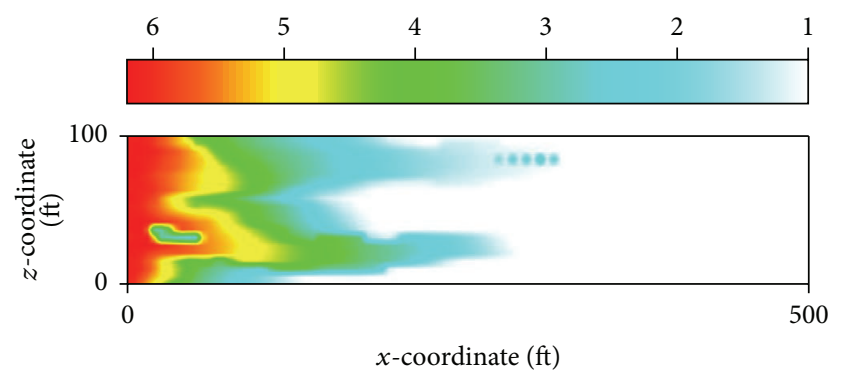

(a) Non-preflush

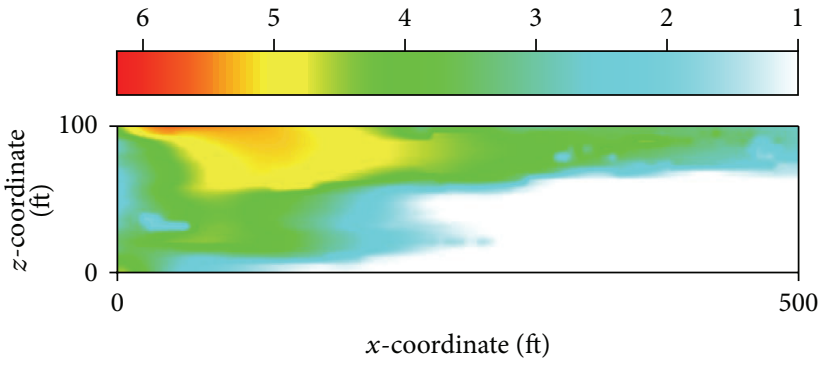

(b) Preflush at 255 days

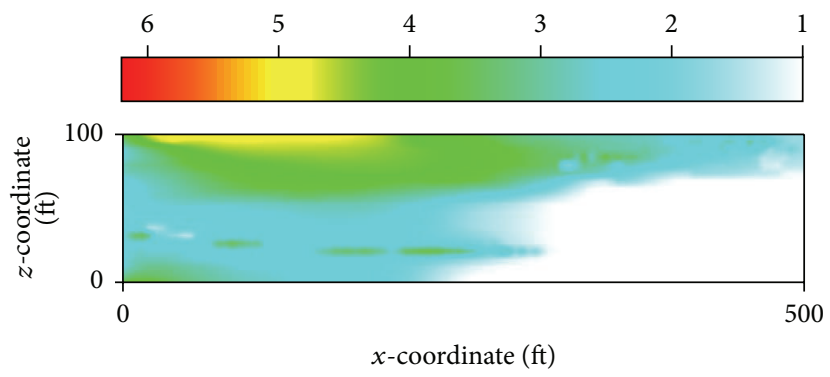

(c) Preflush at 510 days

Figure 6: Permeability reduction factors depending on preflush at 1,000 days.

TABLE 8: Effects of gel treatment and preflush on water-oil ratio and cumulative oil.

\begin{tabular}{lccc}
\hline & $\begin{array}{c}\text { Preflush } \\
\text { (days) }\end{array}$ & $\begin{array}{c}\text { Water-oil } \\
\text { ratio }\end{array}$ & $\begin{array}{c}\text { Cumulative oil } \\
\text { recovery }\end{array}$ \\
\hline $\begin{array}{l}\text { Nontreated } \\
\text { waterflooding }\end{array}$ & & 54 & 0.56 \\
Gel-treated & 0 & 24 & 0.55 \\
waterflooding & 255 & 21 & 0.56 \\
& 510 & 17 & 0.54 \\
\hline
\end{tabular}

it is pretty accurate and effective to explain trend for each case. From the results of Ex 1 and 4, we can conclude that higher heterogeneity index originating from multiscale leads to higher improvement of gel treatment performance on the fields. although Ex 2 and 4 show similar heterogeneity as 0.788 and 0.733 , there is considerable difference in the improvements of gel treatment, up to $14 \%$ because of different spatial distribution of permeability. Ex 5 has the highest heterogeneity over 0.8 , but improvement of water-oil ratio is not that much high due to less layered spatial distribution of permeability. The maximum improvement of Ex 5 does not exceed $70 \%$. These results show that performance of gel treatment is affected by not only heterogeneity index but also spatial distribution of permeability.

To be a successful gel treatment, gel solution should travel to the whole domain of a field and locate at high-permeability zones intensively. To accomplish this goal, preflush as waterflooding is used as one of controllers. Usually, preflush is used to mitigate salinity effect, cation exchange, and so on. In addition, it regulates the placement of gel in fields. Except for preflush duration, all conditions are maintained to be the same as in previous study. Gel treatment is applied on the heterogeneous permeability field of Ex 5, as shown in Figure 1(f). As shown in Table 8, with more preflush, lower water-oil ratio was obtained at the end of the production. Figure 6 shows that the duration of preflush, that is, initiation time of injecting gelant, impacts the distribution of gel into reservoir. No improvement of cumulative oil recovery is observed. Although non-preflush case just reduces $56 \%$ of water-oil ratio, preflush cases for 255 and 510 days show $61 \%$ and $69 \%$ reduction of water-oil ratio.

\section{Conclusions}

(1) In stochastic random field generation, correlation length and number of scales describe spatial distribution of permeability, and variance defines appearance of high-permeability value. Multiscale correlation generally realizes severe heterogeneous permeability fields having higher heterogeneity index.

(2) Reduction of water-oil ratio by gel treatment is a function of heterogeneity index and spatial distribution of permeability originating from correlation length, variance, and number of scales. Generally, longer correlation length, higher variance, and multiscale lead to higher performance of gel treatment.

(3) Preflush influences location of gelation in the reservoir, so it determines performance of gel treatment, that is, reduction of water-oil ratio. Therefore, optimal design of preflush should be considered for successful application of gel treatment. 


\section{Acknowledgments}

This work was supported by the Energy Efficiency \& Resources of the Korea Institute of Energy Technology Evaluation and Planning (KETEP) Grant funded by the Korean Government, Ministry of Knowledge Economy (20122010300020).

\section{References}

[1] H. K. Van Poolen, Fundamentals of Enhanced Oil Recovery, PennWell, Tulsa, Okla, USA.

[2] L. W. Lake, Fundamentals of Enhanced Oil Recovery, The University of Texas, Austin, Tex, USA.

[3] J. T. Portwood, S. H. Lackey, and S. W. Abel, "Selective polymer treatments improve oil recovery in five mature Southern Oklahoma waterfloods," in Proceedings of the 17th SPE Improved Oil Recovery Symposium (IOR '10), SPE 129796, Tulsa, Oklahoma, USA, April 2010.

[4] C. A. Norman and J. E. Smith, "Economics of in-depth polymer gel process," in Proceedings of the SPE Rocky Mountain Regional Meeting, SPE 55632-MS, pp. 15-18, Gillette, Wyo, USA, May1999.

[5] J. J. Sheng, Modern Chemcial Enhanced Oil Recovery: Theory and Practice, Elsevier, Oxford, UK.

[6] J. P. Coste, Y. Liu, B. Bai, Y. LI, and P. Shen, "In-depth fluid diversion by pre-gelled particleslaboratory study and pilot testing," in Proceedings of the SPE/DOE Improved Oil Recovery Symposium (IOR '12), SPE 59362-MS, pp. 3-5, Tulsa, Okla, USA, April 2012.

[7] B. Bai, Y. Liu, J.-P. Coste, and L. Li, "Preformed particle gel for conformance control: transport mechanism through porous media," SPE Reservoir Evaluation and Engineering, vol. 10, no. 2, pp. 176-184, 2007.

[8] B. Bai, L. Li, Y. Liu, H. Liu, Z. Wang, and C. You, "Preformed particle gel for conformance control: factors affecting its properties and applications," SPE Reservoir Evaluation and Engineering, vol. 10, no. 4, pp. 415-422, 2007.

[9] R. S. Seright, "Use of preformed gels for conformance control in fractured systems," SPE Production \& Facilities, vol. 12, no. 1, pp. 59-65, 1997.

[10] R. S. Seright, “Gel propagation through fractures," SPE Production \& Facilities, vol. 16, no. 4, pp. 225-231, 2001.

[11] R. S. Seright, "Disproportionate permeability reduction with pore-filling gels," SPE Journal, vol. 14, no. 1, pp. 5-13, 2009.

[12] G. Chauveteau, A. Omari, R. Tabary, M. Renard, J. Veerapen, and J. Rose, "New size-controlled microgels for oil production," in Proceedings of the SPE International Symposium on Oilfield Chemistry, SPE 64988-MS, pp. 111-118, Houston, Tex, USA, February 2001.

[13] H. W. Gao and T. E. Burchfield, "The effects of crossflow and layer permeability contrast on the effectiveness of gel treatments in polymer floods and waterfloods," SPE Reservoir Engineering, vol. 10, no. 2, pp. 129-135, 1995.

[14] B. Bai, Q. Wang, Y. Du, and Y. Z. Liu, "Factors affecting in-depth gel treatment for reservoirs with thick heterogeneous oil layers," in Proceedings of the Canadian International Petroleum Conference 55th Annual Technical Meeting, SPE 2004-140, Alberta, Canada, June 2004.

[15] R. S. Seright, G. Zhang, O. O. Akanni, and D. Wang, "A comparison of polymer flooding with in-depth profile modification," in Proceedings of the Canadian Unconventional Resources Conference (CURC '11), pp. 128-140, Alberta, Canada, November 2011.
[16] R. B. Gharbi, E. J. Peters, A. Elkamel, and N. Afzal, "Effect of heterogeneity on the performance of EOR processes with horizontal wells," in Proceedings of the SPE Western Regional Meeting, SPE 38320, Long Beach, Calif, USA, June 1997.

[17] S. Murata, A. Ashida, S. Takahashi, and H. Okabe, "Numerical study on effective in-depth profile modification to heterogeneous reservoir," in Proceeding of the 33rd IEA EOR Annual Symposium, Saskatchewan, Canada, 2012.

[18] B. X. Hu, J. Wu, A. K. Panorska, D. Zhang, and C. He, "Stochastic study on groundwater flow and solute transport in a porous medium with multi-scale heterogeneity," Advances in Water Resources, vol. 26, no. 5, pp. 541-560, 2003.

[19] B. X. Hu, J. Wu, and C. He, "On stochastic modeling of groundwater flow and solute transport in multi-scale heterogeneous formations," Computational and Applied Mathematics, vol. 23, no. 2-3, pp. 121-151, 2004.

[20] C. Cozic, D. Rousseau, and R. Tabary, "Novel insights into microgel systems for water control," SPE Production \& Operations, vol. 24, no. 4, pp. 590-601, 2009.

[21] R. S. Seright, G. Zhang, O. O. Akanni, and D. Wang, "A comparison of polymer flooding with in-depth profile modification," in Canadian Unconventional Resources Conference (CURC '11), SPE 146087-MS, Alberta, Canada, November 2011.

[22] A. Zaitoun, R. Tabary, D. Rousseau et al., "Using microgels to shut off water in a gas storage well," in Proceedings of the SPE International Symposium on Oilfield Chemistry, SPE 106042MS, Houston, Tex, USA, March 2007.

[23] J. Liang, H. Sun, and R. S. Seright, "Reduction of oil and water permeabilities using gels," in Proceedings of the SPE/DOE Enhanced Oil Recovery Symposium (IOR '92), SPE 24195-MS, pp. 22-24, Society of Petroleum Engineers, Tulsa, Okla, USA, April.

[24] J.-T. Liang and R. S. Seright, "Further investigations of why gels reduce water permeability more than oil permeability," SPE Production \& Facilities, vol. 12, no. 4, pp. 225-230, 1997.

[25] G. Chauveteau, R. Tabary, N. Blin, M. Renard, D. Rousseau, and R. Faber, "Disproportionate permeability reduction by soft preformed microgels," in Proceedings of the SPE/DOE 4th Inproved Symposium Oil Recovery, SPE 89390, Tulsa, Oklahoma, USA, April 2004.

[26] D. Rousseau, G. Chauveteau, M. Renard et al., "Rheology and transport in porous media of new water shutoff/conformance control microgels," in Proceedings of the SPE International Symposium on Oilfield Chemistry, SPE 93254, pp. 435-446, Houston, Tex, USA, February 2005.

[27] S. G. Ghori and J. P. Heller, "Computed effect of heterogeneity on well-to-well tracer results," in Proceeding of 5th Canadian/American Conference on Hydrology, Alberta, Canada, 1990.

[28] L. Smith and R. A. Freeze, "Stochastic analysis of steady state groundwater flow in a bounded domain. I. One-dimensional simulations," Water Resources Research, vol. 15, no. 3, pp. 521$528,1979$.

[29] S. G. Ghori, J. P. Heller, and A. K. Singh, "An efficient method of generating random permeability fields by the source point method," Mathematical Geology, vol. 25, no. 5, pp. 559-572, 1993.

[30] S.-G. Li and Q. Liu, "Interactive ground water (IGW)," Environmental Modelling \& Software, vol. 21, no. 3, pp. 417-418, 2006.

[31] Center for Petroleum and Geosystems Engineering, UTCHEM9: 0 A Three-Dimensional Chemical Flood Simulator, University of Texas, Austin, Tex, USA, 2000. 

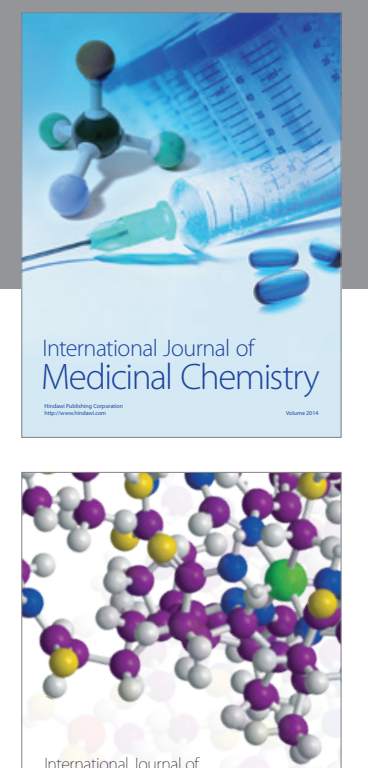

\section{Carbohydrate} Chemistry

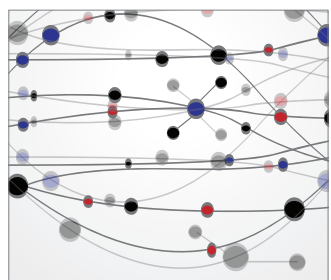

The Scientific World Journal
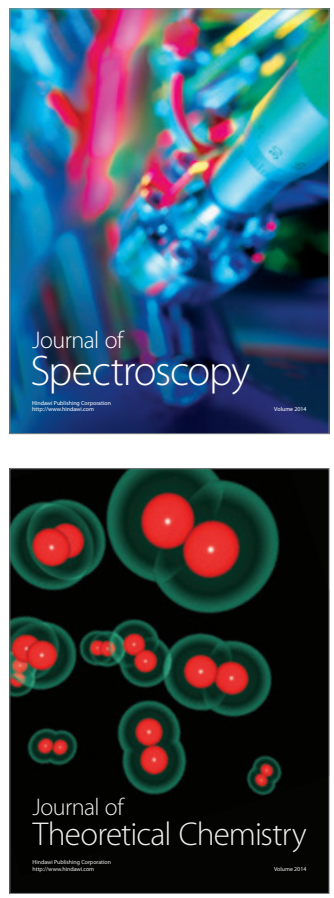
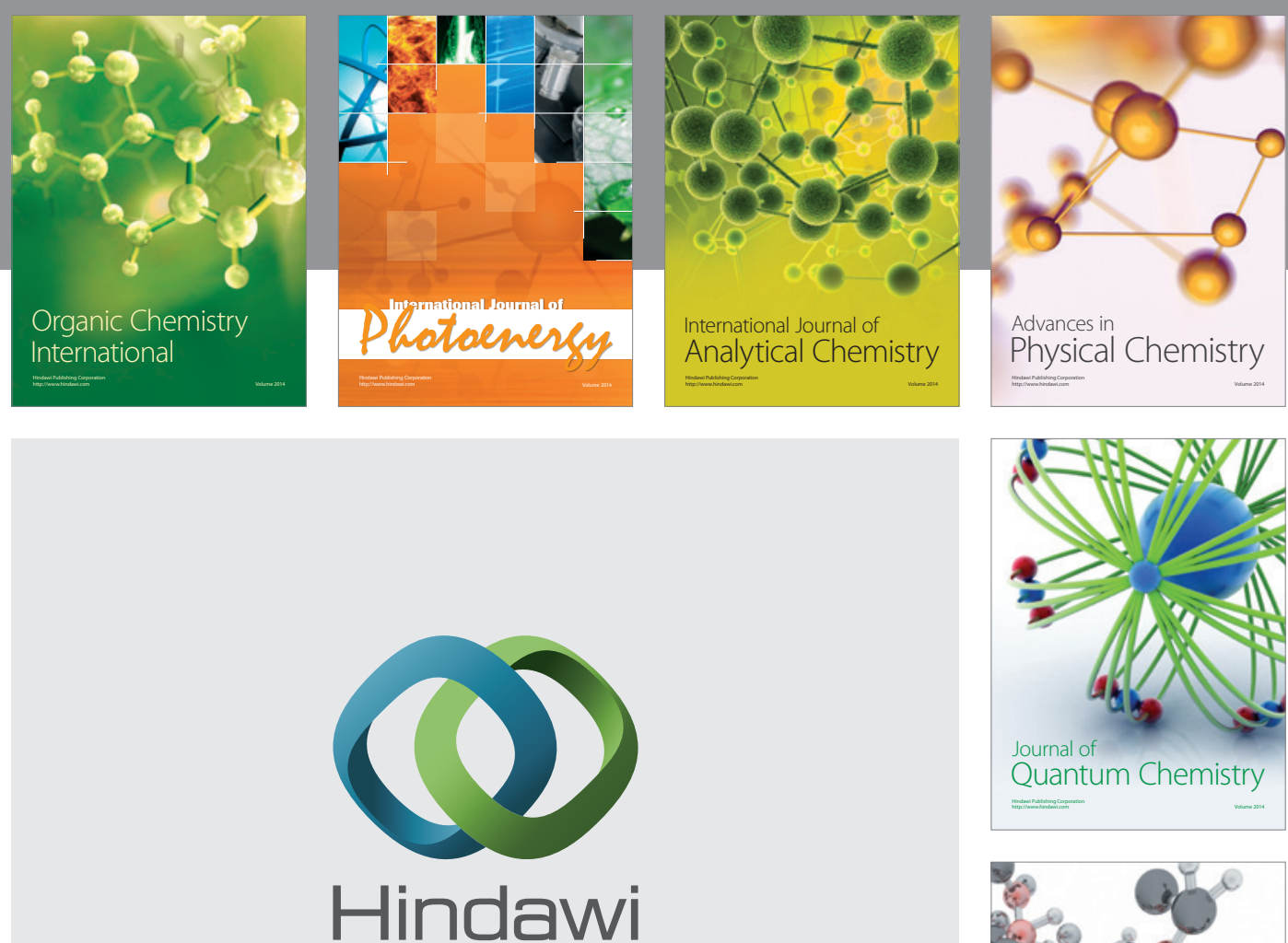

Submit your manuscripts at

http://www.hindawi.com

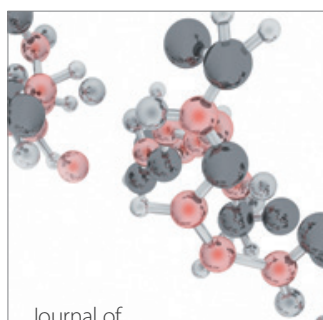

Analytical Methods

in Chemistry

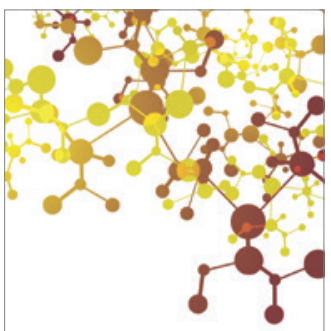

Journal of

Applied Chemistry

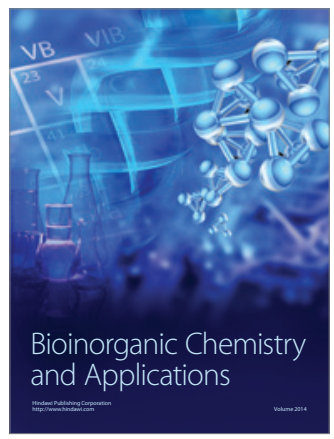

Inorganic Chemistry
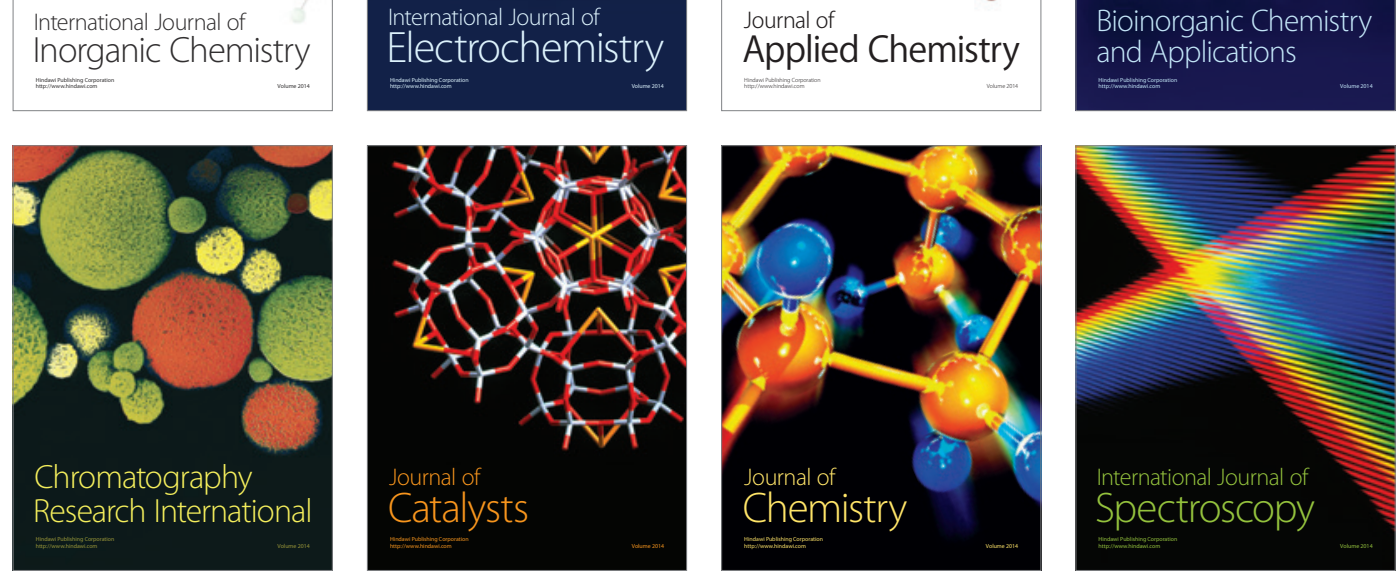